\title{
TWI computation: a comparison of different open source GISs
}

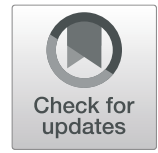

\author{
Pietro Mattivi (D, Francesca Franci, Alessandro Lambertini and Gabriele Bitelli
}

\begin{abstract}
The opportunities of retrieving geospatial datasets as open data and the reliability of Free and Open Source Software (FOSS) GIS increased the possibilities of performing a large number of geospatial analyses. In particular, the worldwide availability of Digital Elevation Model (DEM) permits to compute several topographic indexes able to characterize the land morphology.

In this paper, we evaluate the performances of different open source GIS in the calculation of the Topographic Wetness Index (TWI), a widespread index in hydrological analysis that describes the tendency of an area to accumulate water. Nowadays, there is a large number of available open source desktop GIS, maintained as FOSS projects, each of them focusing on developing specific goals. Therefore, from user point of view, the choice of the best software in solving a particular task is influenced by the GIS specific features.

The test was performed computing the TWI for the Rio Sinigo basin, in northern Italy. The DEM of the test area has been processed with GRASS GIS, Whitebox GAT and SAGA GIS. In order to identify equal workflows, all the combinations of available algorithms and parameters have been studied for each considered GIS. The final TWI maps produced as output were compared and discussed.
\end{abstract}

Keywords: Topographic wetness index, Morphometric parameters, DEM, FOSS, GIS

\section{Introduction}

The natural processes occurring in a catchment landscape can be analyzed by studying its topography. This analysis can provide information on the geomorphology, hydrogeology and even on biological processes taking place in the basin, leading to a qualitative, but also quantitative, characterization of the area.

The main source of data to conduct this kind of study is represented by the Digital Elevation Model (DEM), from which it is possible to obtain several topographic indexes. The spatial distribution of topographic attributes provides an indirect measure of the spatial variability of the processes taking place in the catchment and, consequently, makes it possible to map them. It is possible to divide these topographic attributes in primary and secondary topographic indexes. The primary topographic indexes are those that can be directly obtained from the elevation data, whilst the secondary topographic indexes are combinations of the

\footnotetext{
* Correspondence: pietro.mattivi2@unibo.it

Department of Civil, Chemical, Environmental, and Materials Engineering, University of Bologna, Viale del Risorgimento 2, Bologna, Italy
}

primary indexes able to describe the spatial variability of specific processes [24].

These topographic attributes can be easily extracted from DEMs using Geographic Information Systems (GIS) or specialized software. These software packages permit to create, manage, analyse and visualize georeferenced data [36]. Nowadays, Free and Open Source Software (FOSS) GIS are a widespread, recognized and rapidly developing counterpart to commercial solutions in the field of GISs $[6,18,26]$.

Free and open source software provide freedoms of use, modification, redistribution to the public and access to the source code. These projects are able to attract users and developers, who influence the software development and support, consequently raising their appeal to new free software users [37]. In fact, virtual and worldwide online platforms are available for users and developers (represented by online source code repository, mailing lists, online manuals and tutorials, etc.), which ease the improvements of the existing code and the implementation of new algorithms and tools. These development model grants advanced and interoperable software to final users, for free [4]. 
There is a large number of available FOSS desktop GISs, which are developed and maintained by just as many free software projects; each of these projects focus its software development on specific functionalities, on the basis of the project goals. As a consequence, different GIS software may be better in solving some tasks than others. Thus, the choice of the most suitable software may be complicated and influenced by the study that has to be performed. In fact, many FOSS desktop GIS users adopt a "multi-GIS use strategy": they switch a number of GIS packages to accomplish different tasks [37].

In this paper we will evaluate the performances of three different FOSS GIS packages on a specific task, from a user point of view. We propose an objective and replicable procedure for the comparison. Our aim is to highlight the differences in the algorithm implementation which may affect the final result.

In the last years, GIS has become a key tool for a wide range of disciplines as geology, climatology, geography, archaeology, oceanography, conservation. The users exploit GIS packages to manage, analyse and represent geospatial data $[19,39]$. The paper is within the scope of water resource research field. The work focuses on the computation of morphometric indexes obtainable from DEMs. In particular, software comparisons are performed calculating a very common and widely used secondary topographic index, the Topographic Wetness Index (TWI).

\section{Case study: the TWI}

The performances of SAGA GIS, GRASS GIS and Whitebox GAT were compared in the field of the morphometric terrain analysis. In order to test the GISs in solving a complex task, we chose the Topographic Wetness Index (TWI). The TWI, being a compound index allowed to test different DEM based algorithms within each GIS environment.

The Topographic Wetness Index (TWI), the most commonly used hydrologically-based topographic index, describes the tendency of a cell to accumulate water; it is defined as follows,

$$
T W I=\ln \left(\frac{S C A}{\tan \phi}\right)
$$

where $S C A$ is the Specific Catchment Area and $\phi$ is the slope angle, assuming the properties of the soil as uniform. The basic concept of the TWI is a massbalance: SCA is a parameter of the tendency to receive water, while the local slope and the draining contour length, implicit in the SCA, describe the tendency to evacuate water (Fig. 1). This index assumes steady-state conditions and, as already pointed out, spatially invariant conditions for infiltration and transmissivity. The index is scaled by the natural logarithm [13].

Areas prone to water accumulation (large contributing drainage areas) and characterized by low slope angle will be linked to high TWI values. On the other hand, well-drained dry areas (steep slopes) are associated to low TWI values. However, which particular TWI values indicate wet soils vary depending on landscape, climate and scale [1].

The SCA is defined as the contributing area per unit width of contour. The contributing area (also known as basin area, upslope area, or flow accumulation) determines the size of the upslope area (derived by the number of cells) draining into a cell. To understand how the water flows on the land surface, and thus to calculate the contributing area, a flow routing algorithm is used. The flow routing algorithm establishes the direction of the flow for every cell [13].

The index has shown good correlations with the real distribution of soil moisture in many small catchments, although it shows some limitations due to the dependence of the index to seasonal changes and other nontopographical variables as soil properties, land-use, vegetation, degree of saturation, and evapotranspiration. In fact, in flat areas this phenomenon is mainly driven by these variables and it is poorly affected by the morphology. As a consequence, the TWI performs badly in a flat landscape [42].

It may be used as a first step to guide sampling and model development in unmapped areas or to enhance existing soil attribute data from soil survey maps and databases [23]. Higginbottom et al. [16] adopted TWI maps for monitoring wetlands status [16], while it has been used by Pourali et al. [29] as cost-efficient approach, compared to conventional hydrodynamic models, to identify flood-prone area [29].

Furthermore, this index has been proved to be very powerful for the investigation of other phenomena: for example, Cohen et al. [5] demonstrated that this index is able to predict household risk of malaria more accurately than land-cover/land-use characteristics, in terrains with high topographic variety [5].

The TWI suffers of some limitations related to its calculation: it is scale-dependent, and it also depends on the method used to compute the drainage flow paths. Ågren et al. [1] conducted some research to understand at which resolution the TWI gives the best approximation of the soil moisture spatial distribution, but unfortunately that seems to depend on landscape features. Therefore, for different applications it might be possible to have different optimal resolutions.

The other great limitation is given by the computation methods, which will be discussed below, comparing three different FOSS GISs. 

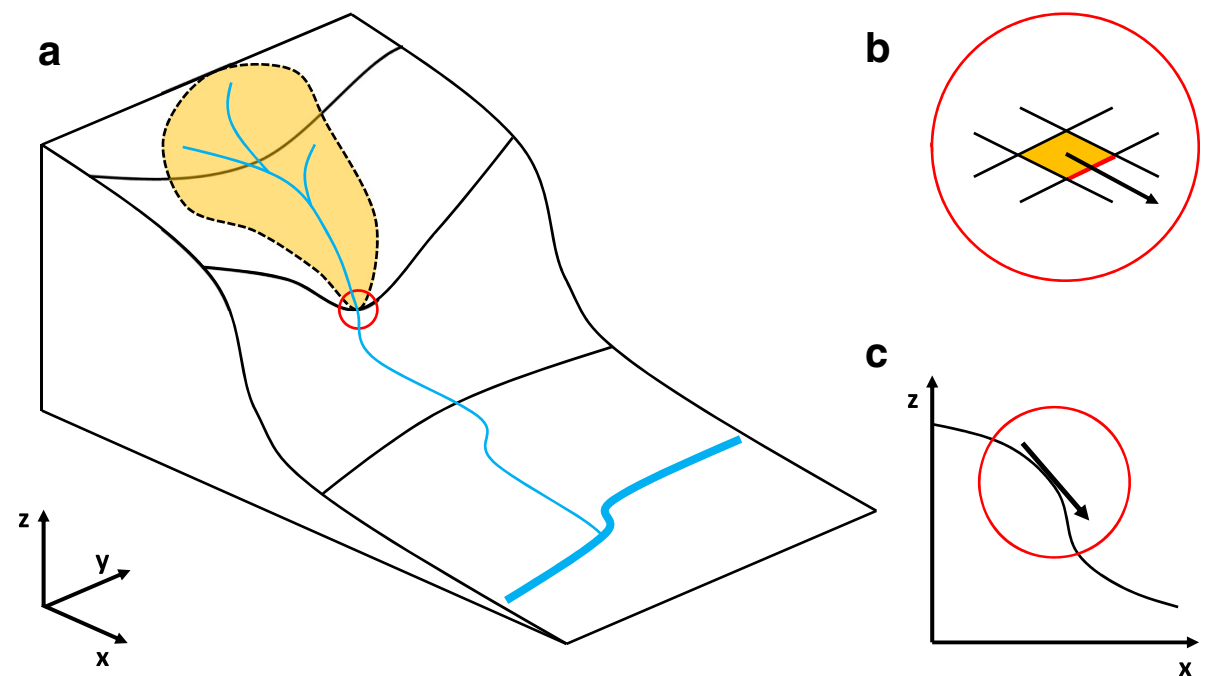

C

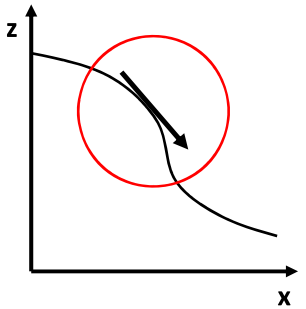

Fig. 1 TWI scheme Scheme of the TWI: a Flow accumulation area, b Flow direction and the corresponding flow width for a DEM cell, c Tangent of the slope angle

\section{Test data}

The TWI will be extracted for the area of the Rio Sinigo basin. This watershed is located near the city of Merano in the autonomous province of Bolzano in northern Italy and it covers an area of $35 \mathrm{~km}^{2}$ (Fig. 2).

The DEM of the Rio Sinigo watershed was extracted from the DEM of the entire province, which has an extension of approximately $7400 \mathrm{~km}^{2}$ with a height ranging from $250 \mathrm{~m}$ to $3900 \mathrm{~m}$ a.s.l.; it was processed with a spatial resolution equal to $10 \mathrm{~m}$. The DEM was produced from a airborne laser scanner survey performed by means of the measurement of the first and last pulse. The survey project was carried out by the province of
Bolzano and the derived products, are freely available as open data on the province's website [30]. The dataset has three different levels of vertical accuracy (standard deviation) for three different environments of the Rio Sinigo, shown in Fig. 3:

1. The area covered by the technical map of the province, mostly valley floors, has a vertical accuracy of $25 \mathrm{~cm}$ (the requested laserpoint density was of minimum 4 points (last pulse) for a $2.5 \mathrm{~m} \times$ $2.5 \mathrm{~m}$ area);

2. The non-mapped areas below $2000 \mathrm{~m}$ of altitude have a vertical accuracy of $40 \mathrm{~cm}$ (the requested

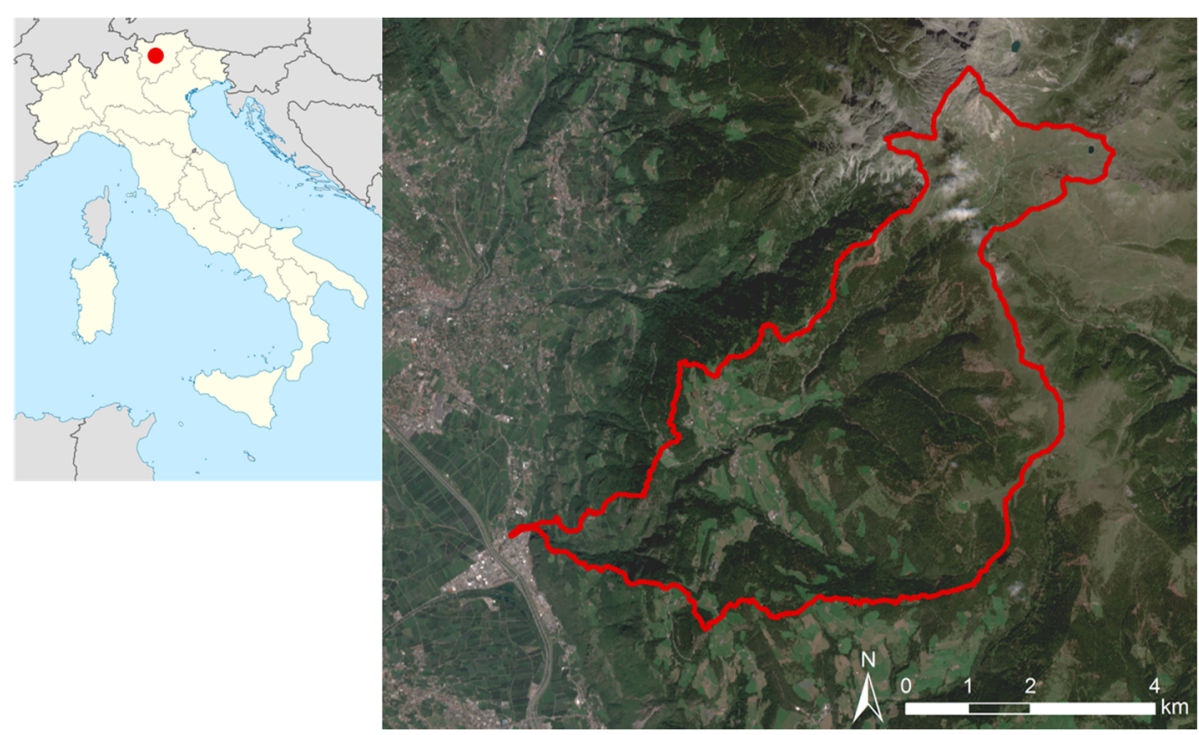

Fig. 2 Test data location Location of the Rio Sinigo basin and the catchment extent on Sentinel-2 image (August 2018) 


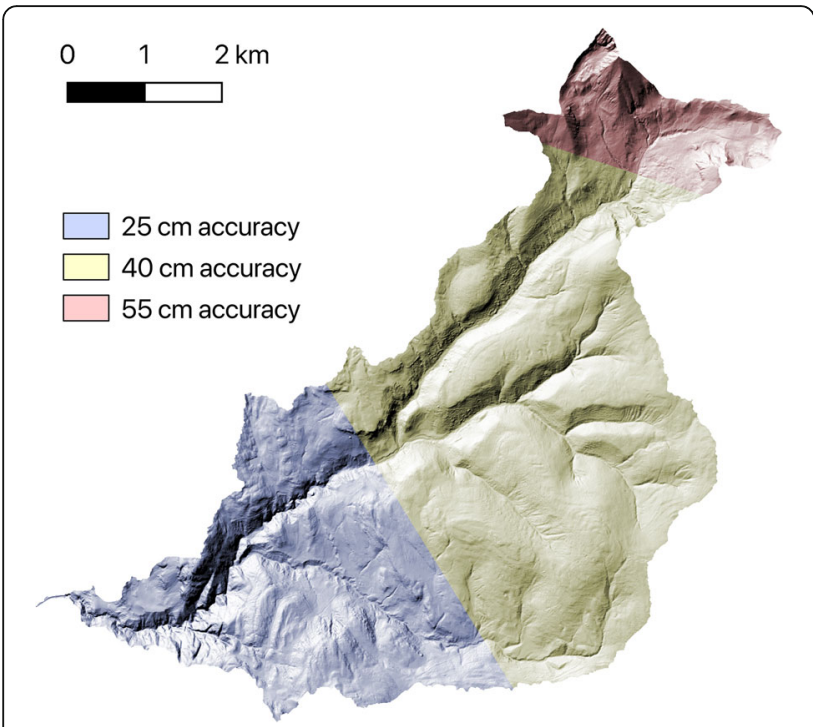

Fig. 3 Regions of different DEM vertical accuracy Regions of different DEM vertical accuracy in the Rio Sinigo basin

laserpoint density was of minimum 8 points (last pulse) for a $5 \mathrm{~m} \times 5 \mathrm{~m}$ area);

3. The areas with an altitude greater than $2000 \mathrm{~m}$ above sea level have a vertical accuracy of $55 \mathrm{~cm}$ (the requested laserpoint density was of minimum 3 points (last pulse) for a $5 \mathrm{~m} \times 5 \mathrm{~m}$ area).

The data are provided in the ETRS89/UTM system.

\section{Methods}

In order to evaluate the potential of each GIS package, we identified all the available tools and algorithms for the TWI computation. This step permitted to investigate the possibility offered by each GIS. As a consequence, we were able to assess the freedom given to the user in setting the index extraction.

The software packages used to extract the TWI from the DEM are: SAGA GIS (7.1.1), GRASS GIS (7.6.1) and Whitebox GAT $(3.4 .0)$ [6, 22, 25]. In Fig. 4 the possible combinations of tools and algorithms, for the computation of the index, are shown.

To detect the differences in the final product, attributable only to the software choice, possible "common paths" in the index extraction were recognized for each package. We defined "common path" as a sequence of tools using the same algorithms for the same task. We identified two "common paths": one common to all the packages (Path 1) and one common only to SAGA GIS and Whitebox GAT (Path 2), colored in red and blue in Fig. 4, respectively.

Finally, to compare the results, a simple difference in absolute value between the TWI maps was computed.

\section{Implementation of the TWI computation in the GIS packages}

As already mentioned, the TWI is sensitive to the algorithms used to compute it. Therefore, the methods used for the calculation of the slope and the SCA are crucial.

To calculate the SCA it is necessary to compute the flow accumulation first, which can be obtained with several different algorithms. The contributing area, and thus the SCA, depends strongly on how the potentially contributing flow is partitioned from a center cell to its downslope neighbors, and this depends on the chosen algorithm. Usually flow routing algorithm are categorized into two types: single-direction and multipledirection algorithms. Single-direction algorithms assume that water drains from the center cell to one downslope neighboring cell, while multiple-direction ones are able to subdivide the flow to more than one downslope neighboring cell [8]. Different flow routing algorithms can lead to great differences in the final products.

\section{Grass GIS}

The Geographic Resource Analysis Support System (GRASS) manages raster, vector, point data and contains image processing modules. Developed by the U.S. Army Corps of Engineers, it was released to public in the 1989 [25]. The GRASS package can be extended through custom modules, which can be written in common programming languages $(\mathrm{C}, \mathrm{C}++$, Python, etc.), or developed by people and institutes from all over the world. GRASS is an official project of the Open Source Geospatial Foundation and since 1997 it is maintained by "The GRASS Research Group” at Baylor University, Waco (Texas), U.S.A.

In this environment, it is possible to obtain the TWI with three different tools. The first one, which is also the specific tool for the extraction of the TWI, is the r.topidx tool.

The second possibility is given by the r.watershed tool (Fig. 4a), which is able to generate many different dataset for the hydrological analysis. Among these maps it is possible to extract the TWI, which is called "topographic index" in this case. The default flow routing algorithm is the Multiple Flow Direction (MFD; $[11,33]$ ), but it is also possible to use the single flow direction algorithm Deterministic 8 (D8) as proposed in O'Callaghan and Mark [27]; it has been however suggested in different works to avoid the calculation of the TWI using single flow direction algorithms [1, 8, 20, 35]. For the MFD algorithm it is possible to set a convergence factor between 1 and 10, the default value being 5 . This value makes the flow accumulation to converge more strongly with higher values.

The last option is the r.terraflow tool (Fig. 4b); similarly to the r.watershed tool, it generates many different spatial datasets and one of them is the TWI, here called "Topographic Convergence Index (TCI)". The default flow 


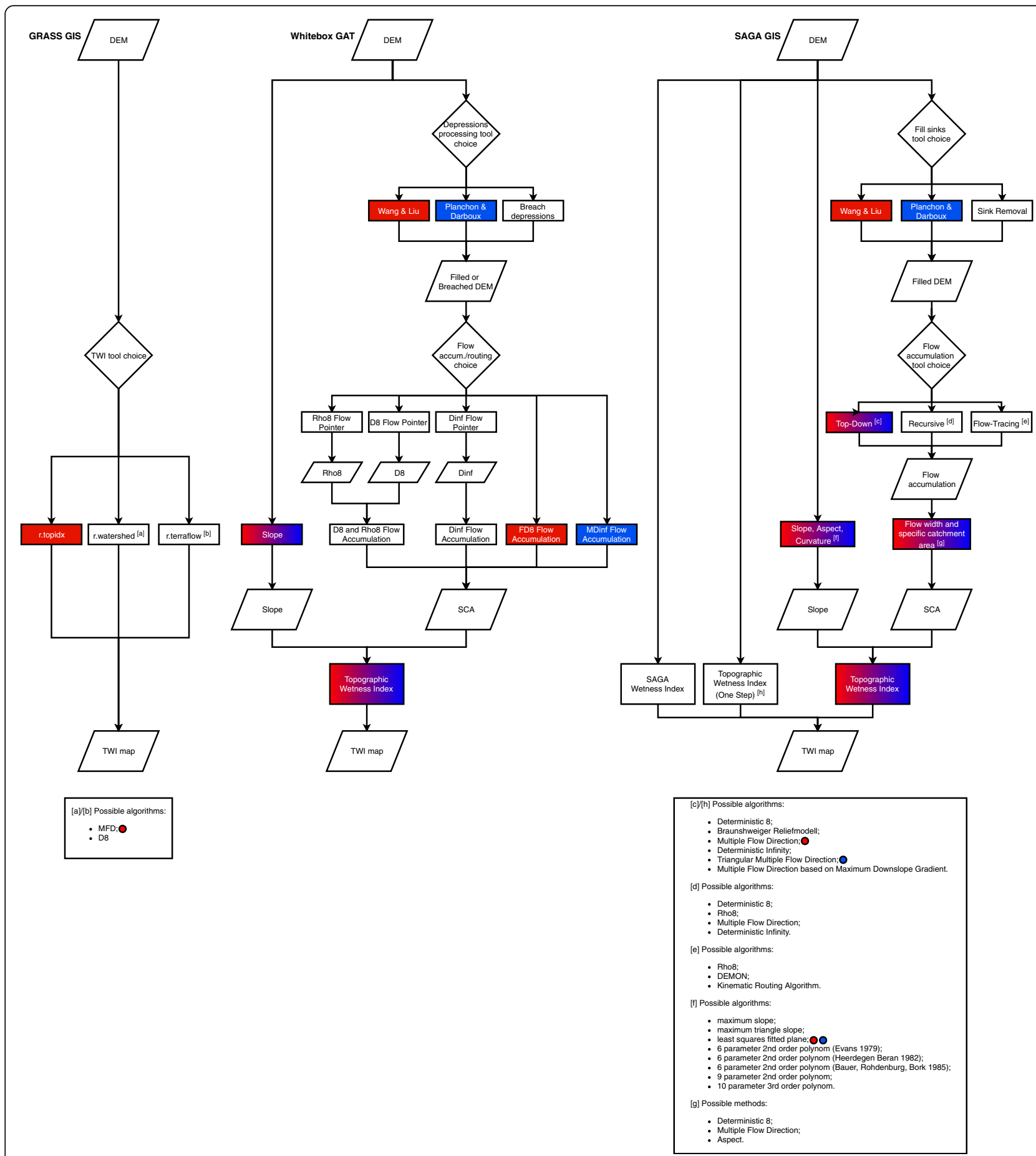

Fig. 4 Tools and algorithms flowchart Flowchart of the tools and algorithms available for the computation of the TWI and "common paths" identified for the analyzed FOSS GISs: "Path 1" highlighted in red; "Path 2" highlighted in blue

routing algorithm is the MFD; also in this case it is possible to choose the D8 algorithm. This tool allows to set a threshold for the flow accumulation. Above the threshold, the flow dispersion will be switched from MFD to D8 in order to represent in a more realistic way the channelization of the water.

\section{Whitebox GAT}

Whitebox Geospatial Analysis Tools (GAT) is an opensource GIS designed to provide a platform for the rapid development and testing of experimental geospatial analysis methods, supported by its extensible design, integrated facilities for custom plug-in tool authoring, and its. 
open-access design philosophy. One of the unique characteristics of Whitebox GAT is the ease with which users can inspect and modify the algorithms for individual geoprocessing tools. The open-access software model that Whitebox GAT adopts is designed to lessen the barriers that are often imposed on end-users when attempting to gain deeper understanding of how a specific function operates. It is a portable application running on the Java Virtual Machine; it is developed using a combination of programming languages targeting the Java Runtime Environment (JRE) including Java, Groovy, Jython (the Python implementation for Java), and Javascript. The Whitebox GAT project began in 2009 through the development efforts of researchers at the University of Guelph, Canada. The project was conceived as a replacement for the Terrain Analysis System, a freeware software package with an emphasis on analysis of digital elevation data [22].

To calculate the TWI with Whitebox GAT the user has to follow a step-by-step approach. Firstly, the DEM has to be hydrologically corrected; the user can choose between the Fill Depression (Wang \& Liu) tool, the Fill Depression (Planchon \& Darboux) and the Breach Depression tool (which is the recommended one by the developers). Then, the corrected DEM can be used to obtain the flow accumulation map. If the desired flow routing algorithm is the Dinf, D8 or Rho8, the user has to run respectively the Dinf Flow Pointer, D8 Flow Pointer or Rho8 Flow Pointer tool first; the maps obtained can be used as input for the D-infinity Flow Accumulation tool or for the D8 and Rho8 Flow Accumulation tool, specifying the specific catchment area (SCA) as output type, to calculate the SCA $[10,38]$. If the user wants to use the TMFD (here called MDinf) or the MFD (here called FD8) flow routing algorithm, the SCA can be directly calculated using the corrected DEM as input for the MDinf Flow Accumulation or the FD8 Flow Accumulation tool, selecting as output type the specific catchment area [34]. The latter tools give also the possibility to set a nondispersive threshold. This threshold establishes the flow accumulation value above which flow dispersion is no longer allowed. Those grid cells with flow-accumulation values above this limit will have their flow routed with a singleflow-direction algorithm similar to the D8 algorithm. Therefore, the flow will be routed entirely to the steepest downslope neighbouring cell. This, under the assumption that flow dispersion is not realistic once flow becomes channelized, while it is opportune on hillslope areas. In addition, the user can set a different exponent parameter, the default value is 1 , to modify the amount of flow dispersion.

The slope map can be computed using the Slope tool, which uses the Horn's method to estimate the slope, taking as input the DEM [17]. If the DEM has different vertical and horizontal units, the user can specify a $\mathrm{Z}$ conversion factor.
Finally, the tool to extract the TWI map is called Wetness Index, which needs as input the SCA map and the slope map.

\section{Saga GIS}

The System for Automated Geoscientific Analyses (SAGA) is an open source GIS, that since its first release in 2004 has rapidly developed from a specialized tool for digital terrain analysis to a comprehensive and globally established GIS platform for scientific analysis and modeling. It is a portable application, so it does not require installation, coded in $\mathrm{C}++$ in an object-oriented design. SAGA has been designed for an easy and effective implementation of spatial algorithms and hence serves as a framework for the development and implementation of geoscientific methods and models. This is possible thanks to an application programming interface (API). In 2005 the SAGA User Group Association was founded to support a sustainable long-term development covering the whole range of user interests. Since 2007, the core development group of SAGA has been situated at the University of Hamburg, coordinating and actively driving the development process [6].

To extract the TWI with SAGA, it is possible to follow two different paths: the step-by-step path or the one step tool. The first step is the pre-processing of the DEM, which can be done with three different tools: the Fill Sinks (Wang \& Liu) tool, the Fill Sinks (Planchon E Darboux) tool and the Sink Removal tool [28, 41].

All of them fill all the depression of the DEM and give as output a depressionless DEM, which can be used as input to compute a Flow Accumulation map. The user can also specify a minimum slope value, that is the minimum slope angle that has to be preserved from cell to cell, or a threshold for the maximum depth of a sink to be considered for removal.

The tools that can be used to extract the flow accumulation map are three: Flow Accumulation (Top-Down), Flow Accumulation (Recursive), Flow Accumulation (Flow-Tracing).

The Flow Accumulation (Top-Down) tool (Fig. 4c) needs as input the filled DEM and gives as output the map of the flow accumulation, computed by processing the DEM from the highest cell to the lowest cell. This tool allows to choose the output unit between the cell area and the number of cells, and to set a threshold for the linear flow, i.e. the possibility to apply a linear flow routing algorithm (D8) to those cells having a flow accumulation greater than an user defined threshold. The flow routing algorithm implemented in the tool are: D8, Braunschweiger Reliefmodell, Rho 8, MFD, Deterministic Infinity (Dinf), Triangular Multiple Flow Direction (TMFD) and Multiple Flow Direction based on Maximum Downslope Gradient (MFD-md) [2, 10, 32, 34, 
38]. If the MFD algorithm or the TMFD algorithm are chosen, it is possible to define the convergence factor, which default value is 1.1 .

The second possible tool is the Flow Accumulation (Recursive) tool (Fig. 4d). The input required is the filled DEM and the output is the flow accumulation map. This tool processes recursively all upwards connected cells until each cell of the DEM has been processed. The flow routing algorithms that can be choose are: D8, Rho 8, MFD and Dinf. The user can choose to express the flow accumulation in cell area or in number of cells.

The third available tool is the Flow Accumulation (Flow Tracing) (Fig. 4e): it traces the flow of each cell in a DEM separately until it leaves the DEM or ends in a sink. As for the other tools the user can choose the unit (between cell area and number of cells) and the flow routing method among the kinematic routing algorithm [21], DEMON [7] and Rho8. For the Rho8 method the tool adopts the original algorithm only for the flow routing and that will give different results. It is also possible to choose to apply a flow correction.

From the flow accumulation map, which is none but the total catchment area (TCA), it is possible to compute the SCA using the Flow Width and Specific Catchment Area tool (Fig. 4f). This tool needs as input the filled DEM and the Flow Accumulation map. They are generated by one of the previously described tools. The outputs are the Flow Width and the SCA, needed for the extraction of the TWI. The available methods to calculate these outputs are the following: D8, MFD and Aspect.

To generate the TWI it is also necessary to compute the slope map: the dedicated tool is called Slope, Aspect, Curvature (Fig. 4g). This tool allows the generation of the slope, aspect and curvature map, taking as input the DEM. The user can choose the method to compute the slope map among the following models: maximum slope - Travis, maximum triangle slope - Tarboton, least squares fitted plane - Horn $\backslash$ Costa-Cabral, 6 parameter 2nd order polynom - Evans, 6 parameter 2nd order polynom - Heerdegen, 6 parameter 2nd order polynom Bauer, 9 parameter 2nd order polynom - Zevenbergen and 10 parameter 3rd order polynom - Haralick [2, 7, 9, $14,15,17,38,40,43]$. The user can also define the unit of the output among radians, degree and percent; in this case, it is important to leave the unit of output in radians, otherwise it will lead to errors in the TWI calculation.

The last step corresponds to the generation of the TWI by mean of the Topographic Wetness Index (TWI) tool. This tool requires as inputs the slope and the SCA maps. It is also possible to give as input the slope and the TCA, but in that case the user has to set the area conversion to " $1 /$ cell size (pseudo specific catchment area)"; however, it is better to provide directly as input the SCA. The user can also choose between two options to generate the TWI: the Standard method and the TOPMODEL method.

Furthermore, SAGA GIS offers the possibility to compute the TWI in a single step using the Topographic Wetness Index (One Step) tool. This tool only needs as input the DEM and the user just has to set the preferred flow routing algorithm among the following: D8, Braunschweiger Reliefmodell, Rho 8, MFD, Dinf, TMFD and MFD-md. This tool directly gives as output the TWI map. The Topographic Wetness Index (One Step) tool is a tool chain, in which the DEM is preprocessed with the Sink Removal tool and the slope is computed using the Slope, Aspect, Curvature tool, then the TWI is computed using the following tools in sequence: Flow Accumulation (Top-Down), Flow Width and Specific Catchment Area, Topographic Wetness Index (TWI). The user has only to specify the algorithm used to route the flow in the flow accumulation computation, all the other settings are left as default: this means, for example, that the threshold for the linear flow is always set to 500 .

In addition, it is worth mentioning the SAGA Wetness Index tool, which computes the Topographic Wetness Index as before, but modifies the calculation of the catchment area. This method does not consider the flow as a very thin film. Consequently, the cells located in valley floors, with a small vertical distance to a channel, result in a more realistic soil moisture potential compared to the TWI calculated with the standard catchment area [3].

\section{Results and discussion}

The identification of the common path was quite straightforward for SAGA GIS and Whitebox GAT, while it was harder for GRASS GIS, which calculates the TWI with a one-step tool, without clarifying or documenting the implemented algorithms. The available algorithms are resumed in the Table 1.

The algorithms have been grouped in four categories, considering the three main phases for the TWI computation and the one step procedure, in order to highlight the differences in the algorithms availability and the degree of freedom of choice given to the user. The table shows that SAGA is the most flexible software concerning the algorithm selection in all the considered steps. Whitebox GAT offers a good range of choice, especially in the DEM pre-processing phase, but it has not implemented a one-step tool for the TWI calculation. GRASS is the GIS package with less algorithm choice.

We were able to identify the following two "common paths" to extract the TWI:

Path 1 Wang \& Liu (DEM pre-processing, for SAGA GIS and Whitebox GAT), Horn (Slope, common to all 
Table 1 List of the available algorithms Algorithms suggested for TWI computation in each GIS package, grouped by phase of processing

\begin{tabular}{|c|c|c|c|c|}
\hline & & GRASS & WHITEBOX GAT & SAGA \\
\hline \multirow{4}{*}{ Pre-processing } & Fill depressions (Wang \& Liu) & - & $\bullet$ & $\bullet$ \\
\hline & Fill depressions (Planchon \& Darboux) & - & $\bullet$ & $\bullet$ \\
\hline & Sink Removal & - & - & $\bullet$ \\
\hline & Breach depressions & - & $\bullet$ & - \\
\hline \multirow{9}{*}{$\begin{array}{l}\text { Specific Catchment } \\
\text { Area: Flow routing } \\
\text { algorithm }\end{array}$} & D8 & $\bullet$ & $\bullet$ & $\bullet$ \\
\hline & Rho8 & - & $\bullet$ & $\bullet$ \\
\hline & Dinf & - & $\bullet$ & $\bullet$ \\
\hline & Braunschweiger reliefmodell & - & - & $\bullet$ \\
\hline & MFD & $\bullet$ & $\bullet$ & $\bullet$ \\
\hline & TMFD & - & $\bullet$ & $\bullet$ \\
\hline & MFD-md & - & - & $\bullet$ \\
\hline & DEMON & - & - & $\bullet$ \\
\hline & Kinematic Routing Algorithm & - & - & $\bullet$ \\
\hline \multirow{8}{*}{ Slope } & Maximum slope (Travis et al. 1975) & - & - & $\bullet$ \\
\hline & Maximum triangle slope (Taborton 1997) & - & - & $\bullet$ \\
\hline & Least squares fitted plane (Horn 1981, Costa-Cabral Burgess 1996) & $\bullet$ & $\bullet$ & $\bullet$ \\
\hline & 6 parameter 2nd order polynom (Evans 1979) & - & - & $\bullet$ \\
\hline & 6 parameter 2nd order polynom (Heerdegen Beran 1982) & - & - & $\bullet$ \\
\hline & 6 parameter 2nd order polynom (Bauer, Rohdenburk, Bork 1985) & - & - & $\bullet$ \\
\hline & 9 parameter 2nd order polynom (Zevenbergen Thorne 1987) & - & - & $\bullet$ \\
\hline & 10 parameter 3rd order polynom (Haralick 1983) & - & - & $\bullet$ \\
\hline
\end{tabular}

packages), MFD/FD8 (flow accumulation, common to all packages);

Path 2 Planchon E Darboux (DEM pre-processing), Horn (Slope), TMFD/MDinf (Flow accumulation).

The TWI maps obtained following Path 1 are reported in Fig. 5. In general, by visual inspection, it is possible to observe a similar trend of the TWI values for each map. In fact, the three TWI maps highlight similar discharge (brown pixels) and accumulation (blue pixels) areas. Whitebox GAT and SAGA GIS show a similar range of values, while the GRASS GIS product has a lower minimum value and a higher maximum value.

The comparison of these final products has been performed by means of the simple difference in absolute value between the TWI maps. This procedure highlights how the differences in the TWI values are mainly the consequence of GISs operations (Fig. 6).
At first sight, it is clear that the comparison between Whitebox GAT and GRASS GIS, and the one between SAGA GIS and GRASS GIS look almost equal. Confirming that, the TWI maps computed with Whitebox GAT and SAGA GIS are actually very similar, in fact they were extracted using the same algorithms. In these two cases (Fig. 6a, b), the greatest differences are located along the stream network, where the TWI reaches the highest values. The map of the differences between SAGA GIS and Whitebox GAT looks more uniform than those obtained from the comparison with GRASS GIS, with a systematic shift in the TWI values. An offset of $0.2-0.4$ is also reflected in the maximum and minimum value of the TWI maps.

Looking in more detail, it is possible to notice some other areas characterized by high differences in the TWI values. These differences are concentrated where the landscape slope is gentle or flat. Obviously, the algorithms

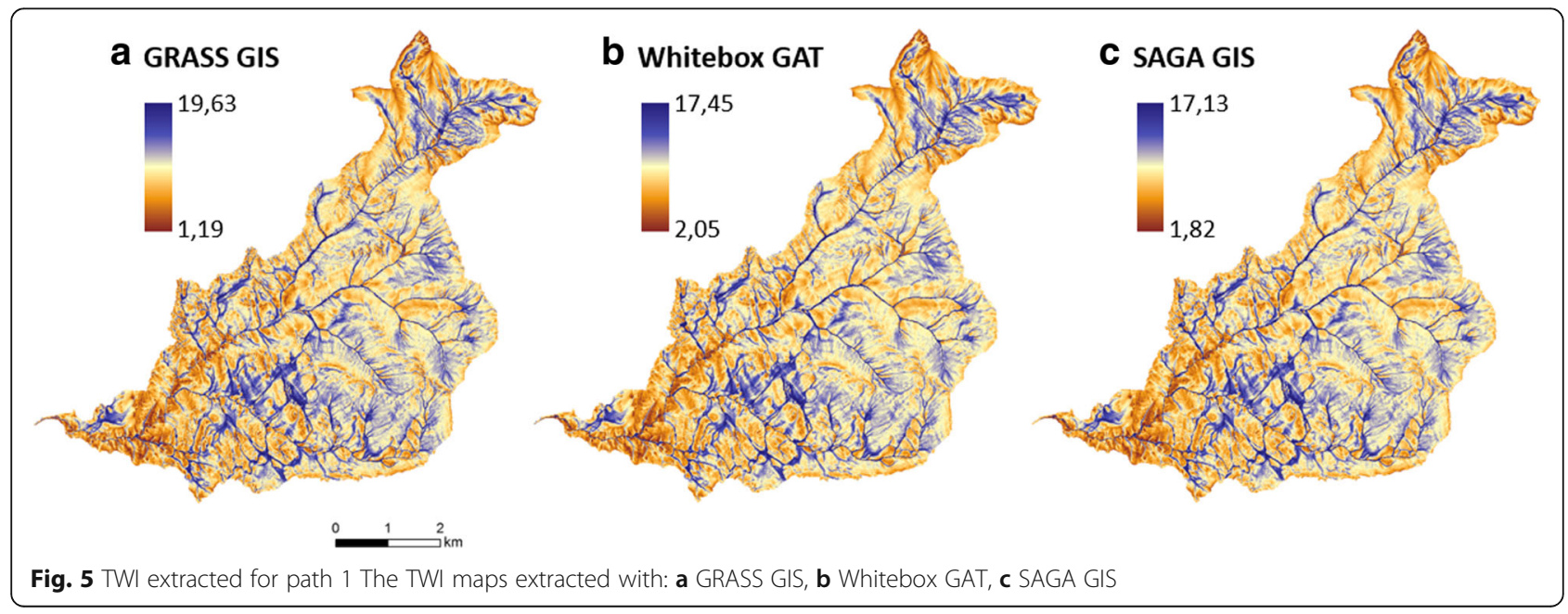




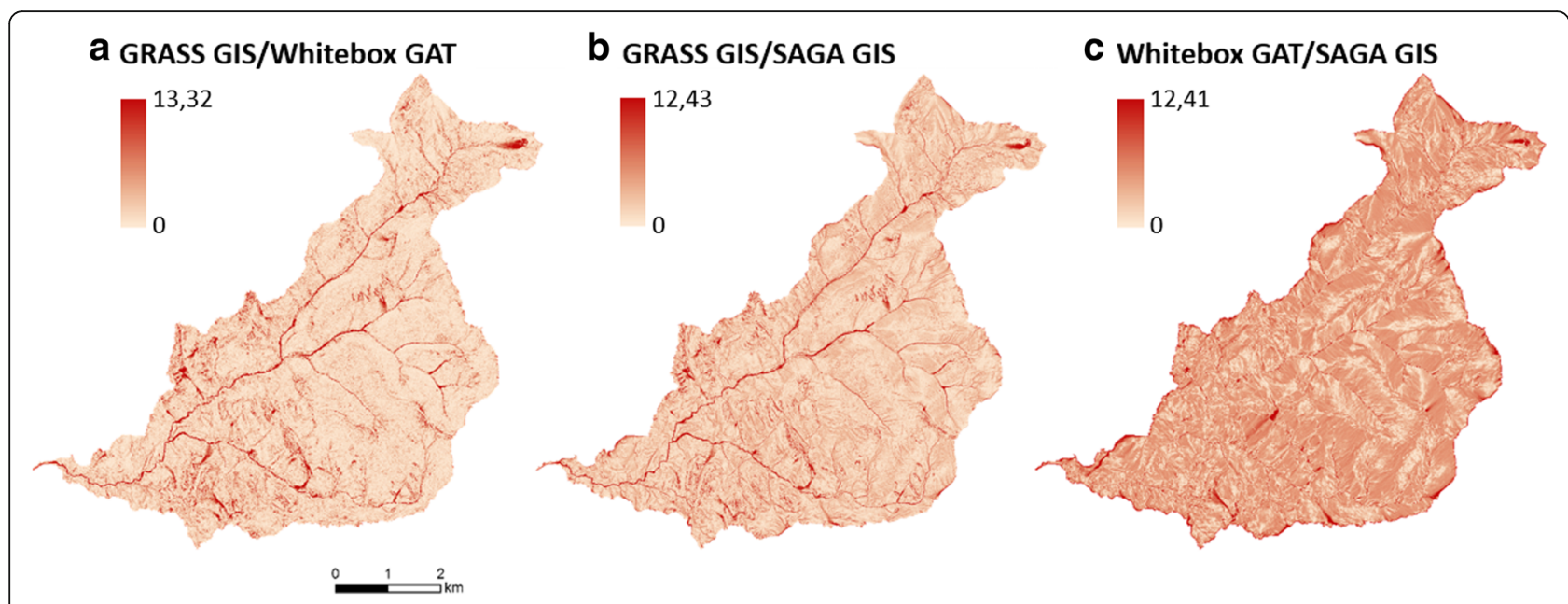

Fig. 6 Comparison of the TWI maps extracted for path 1 Comparison of the TWI maps - Differences in absolute value between the TWI maps obtained with the three GISs: a GRASS GIS/Whitebox GAT, b GRASS GIS/SAGA GIS, c Whitebox GAT/SAGA GIS

have more problem routing the flow in those conditions; however, this highlights how the same algorithm can lead to different results in these cases using different GISs.

Great differences between Whitebox GAT and SAGA GIS are visible also along the borders of the basin.
Particularly interesting is the area downstream of the lake in the northeast part of the basin (Fig. 7), where the flow is routed differently by all the considered packages.

The TWI maps obtained following Path 2 are reported in Fig. 8. As before, the comparison of these final a

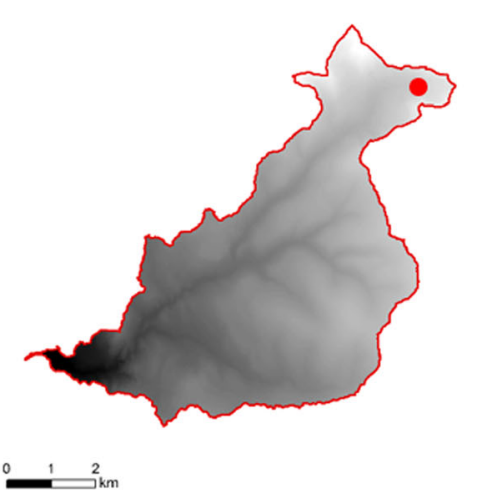

d

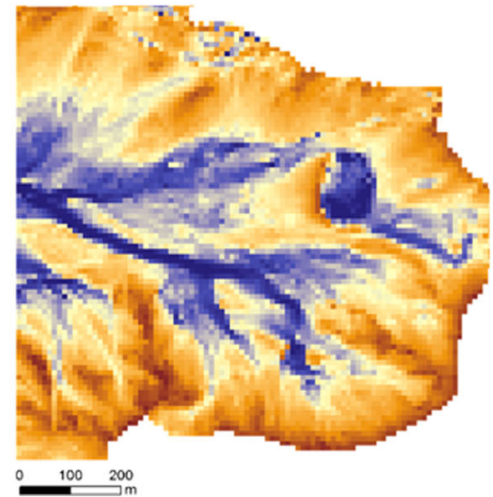

\section{b}

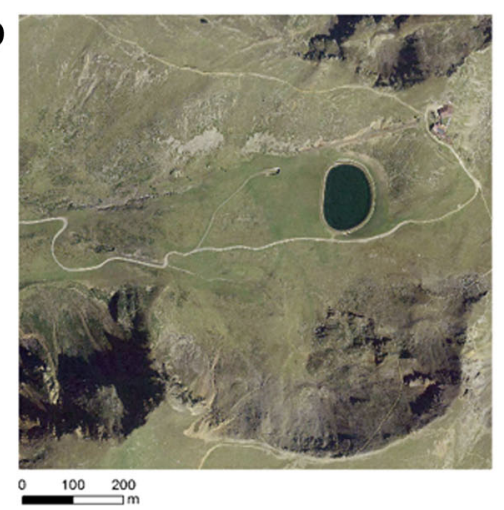

e

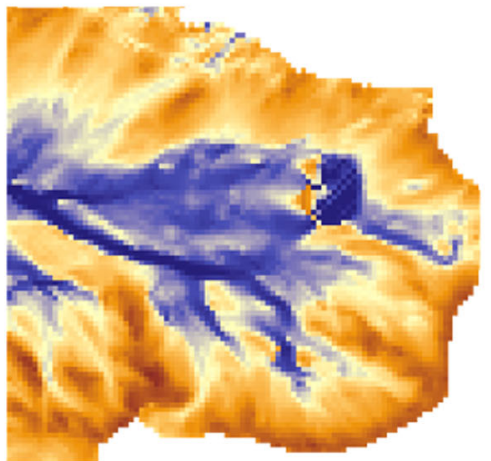

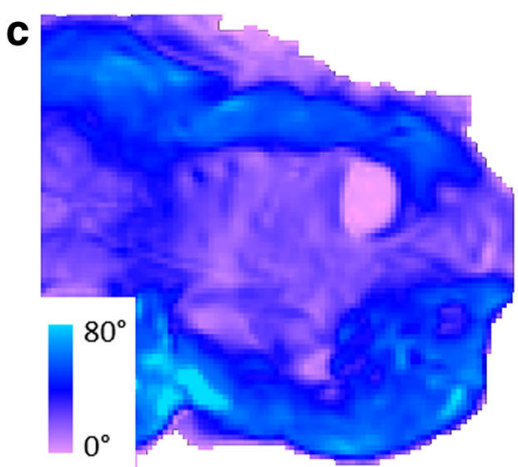

f

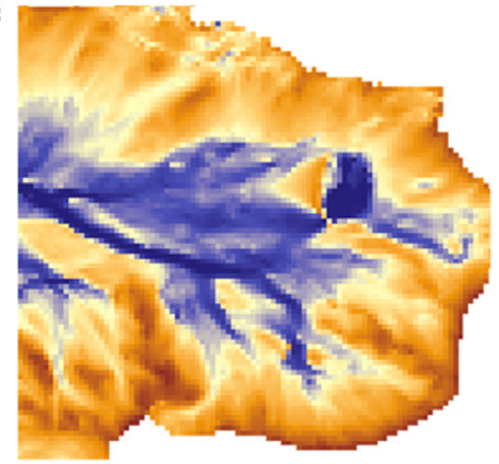

Fig. 7 Detail of the comparison for path 1 Detail of the area near the lake in the northeast part of the basin: $\mathbf{a}$ Location of the area, $\mathbf{b}$ Orthophoto (2011), c Slope map, d GRASS GIS TWI map, e Whitebox GAT TWI map, f SAGA GIS TWI map 


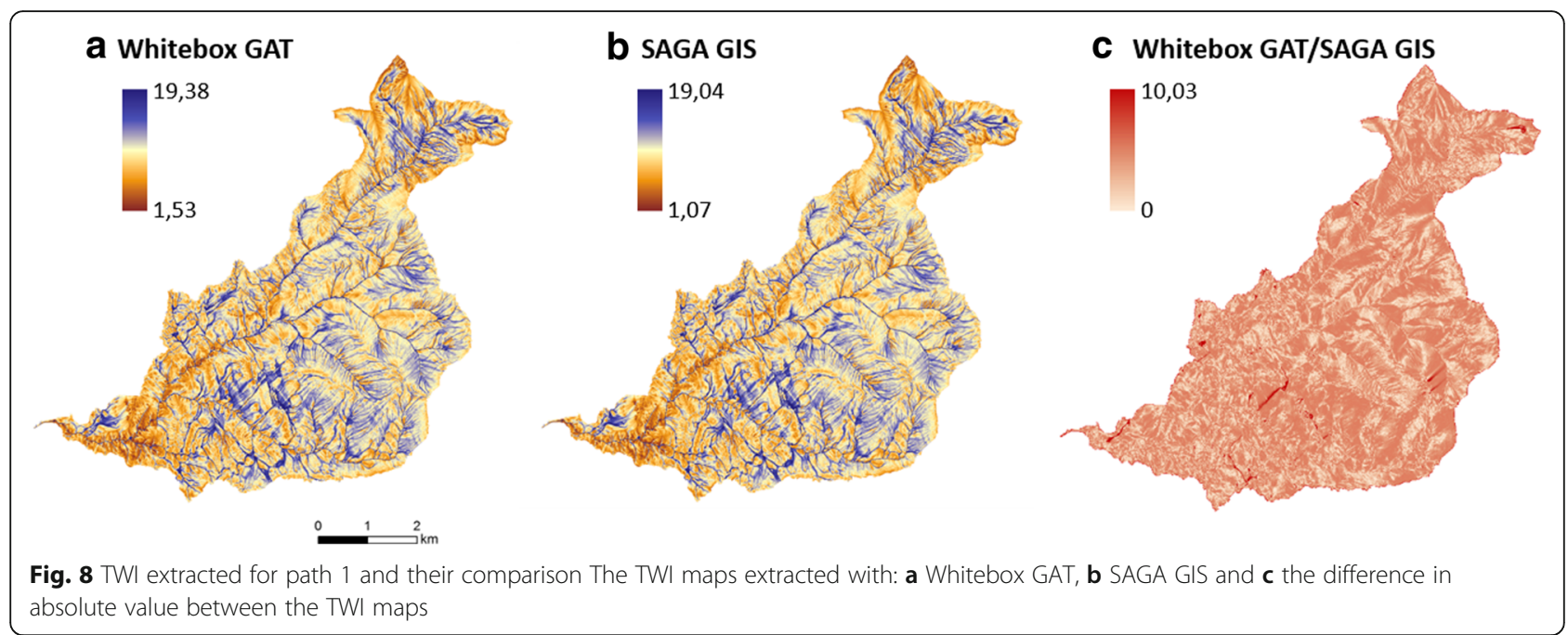

products was made by calculating the simple difference in absolute value between the TWI maps.

The result looks similar to the comparison done for Path 1 between Whitebox GAT and SAGA GIS. The border effects seem to be weakened, but the area with high differences are the same and the general shift between the TWI values all over the basin is yet present.
The detail of an area with high differences is reported in Fig. 9.

The comparison table (Table 2) resumes the evaluation of some key features for the user of the GISs studied for the extraction of the TWI maps. GRASS GIS results less user friendly compared to Whitebox GAT and SAGA GIS. Also the customization of the TWI workflow is limited in
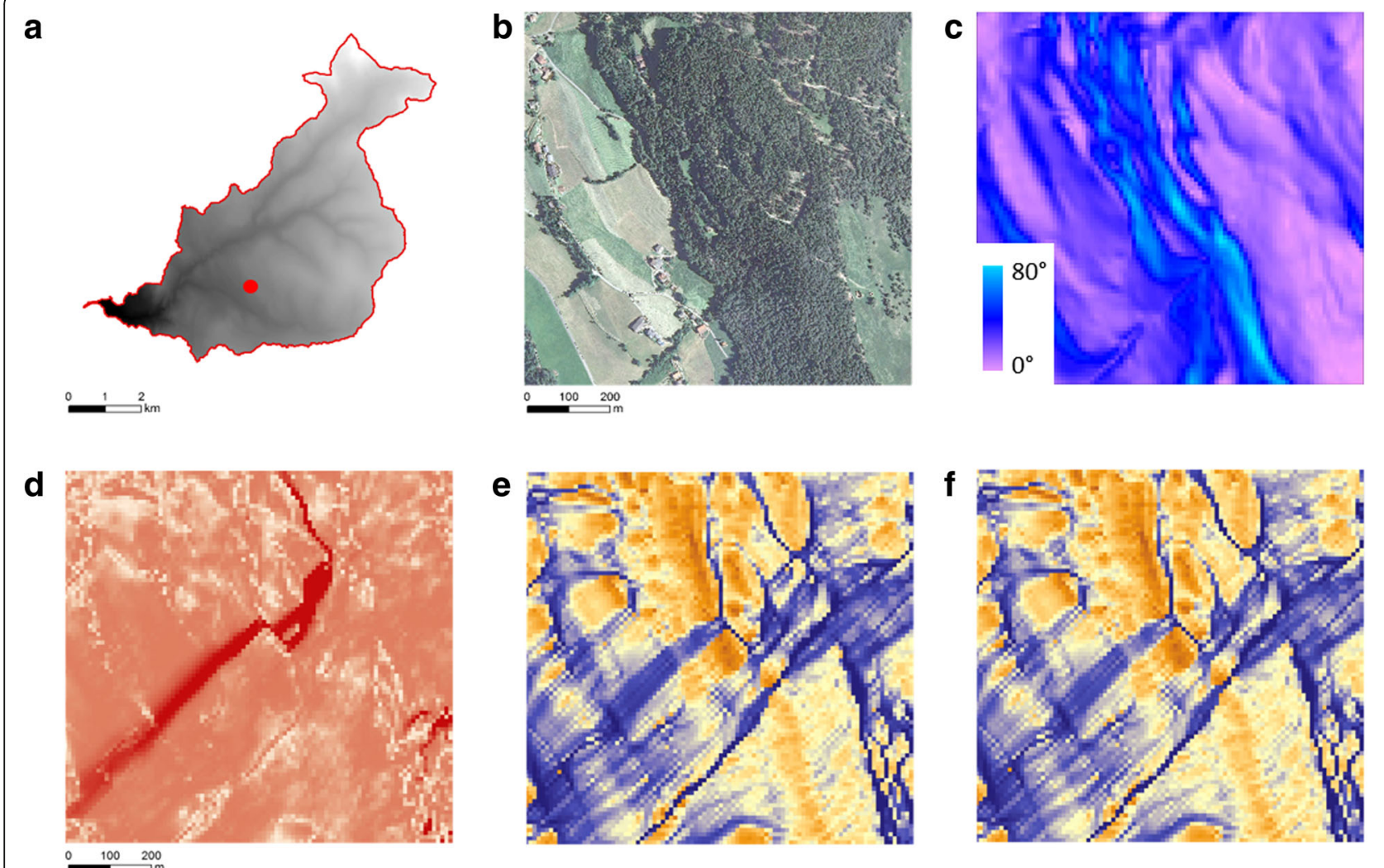

Fig. 9 Detail of the comparison for path 2 Detail of an area showing high differences between TWI values: a Location of the area, $\mathbf{b}$ Orthophoto (2011), c Slope map, d Difference map, e Whitebox GAT TWI map, f SAGA GIS TWI map 
Table 2 GISs comparison table "+" symbol indicates good performance for each feature

\begin{tabular}{llll}
\hline FEATURES & GRASS GIS & WHITEBOX GAT & SAGA GIS \\
\hline User friendliness & - & + & + \\
Workflow customization & - & + & + \\
Algorithms documentation & - & - & - \\
Implementation in QGIS & + & + & - \\
Availability on any operating system & + & + \\
\hline
\end{tabular}

GRASS GIS, which allows to choose only between a singular flow direction algorithm (D8) and a multiple flow direction algorithm (MFD). Whitebox GAT offers a good variety of flow routing algorithms, while SAGA GIS has the most complete choice of algorithms, both for the flow routing and for the slope computation. The tools and the implemented algorithms are very good described in Whitebox GAT. SAGA GIS reports the complete list of the references for every tool and algorithm. Concerning GRASS GIS, the information provided by the standard documentation about the implemented algorithms is more limited, and in some cases the list of references is incomplete.

Nowadays, QGIS is a widely used free and open source GIS package [12] suitable for a variety of applications [31]. Therefore, we considered the implementation of the studied tools in QGIS as an added value in the comparison. The GRASS GIS and SAGA GIS tools are integrated into QGIS; while the algorithms of GRASS GIS are completely available in QGIS, not all the algorithms of SAGA are implemented in QGIS. Also for Whitebox GAT, it is possible to integrate the Whitebox Tools toolset in QGIS, however not all the algorithms are available. GRASS GIS and Whitebox GAT run on Windows, Linux and MacOS operating systems, while SAGA GIS runs only on Windows and Linux operating systems.

\section{Conclusions}

The main goal of this paper was the comprehensive evaluation of three different FOSS GIS for DEM based analysis. Whitebox GAT, GRASS GIS and SAGA GIS were compared for the extraction of the Topographic Wetness Index - TWI. It was calculated for the Rio Sinigo basin starting from a LIDAR based DEM, provided as open data. We followed an objective approach to assess performances, potentialities and differences in the final output for each GIS.

The comparison procedure started with the identification of all the possible workflows for the TWI computation. This phase allowed to explore tools and algorithms offered by each GIS and the achievable level of customization.

Secondly, to highlight the differences in the TWI maps only due to the software algorithm implementation, two equal procedures, called "common paths", were followed. The common paths were defined by selecting the same algorithms in the three GIS packages. A comparable trend on the TWI values has been obtained by the three packages. Similar trend of the TWI values computed by each software have been obtained. Whitebox GAT and SAGA GIS showed similar range of values while GRASS GIS output resulted in a wider range with a lower minimum and an higher maximum values. The comparisons between the TWI maps have been performed computing the simple difference in absolute value. This procedure confirmed the similarity between Whitebox GAT and SAGA GIS maps. We observed the largest discrepancies in correspondence of flat landscape or areas characterized by gentle slope. This demonstrates how the same algorithms can lead to different results using different GISs in critical areas. However, all the packages were able to successfully extract the index with comparable outputs and within a similar processing time. For this reason, it is not possible to declare which software is the best choice for the TWI computation.

Although the good performances of the GIS packages, some of them guarantee a higher level of freedom regarding the algorithms choice and the workflow customization. GRASS GIS showed a limited choice of algorithms and parameters. Whitebox GAT and SAGA GIS offered a large variety of flow algorithms. Moreover, SAGA GIS provided several approaches for the slope computation. Algorithms and tools implemented in Whitebox GAT and SAGA GIS are completely documented while GRASS GIS suffered the lack of some information. In conclusion, depending on the user expertise and goals, some tools may be more suitable than others.

The presented comparison procedure has proved to be simple and objective. This methodology could be effectively extended to other case studies as a standard GIS comparison approach.

Overall the presented work confirms the good level of maturity reached by the studied FOSS GIS, even for complicated tasks. Furthermore, this work highlights the impressive possibilities offered by the FOSS environment for the aforementioned analysis.

\section{Abbreviations}

API: Application Programming Interface; D8: Deterministic 8; DEM: Digital Elevation Model; Dinf: Deterministic Infinity; FOSS: Free and Open Source Software; GIS: Geographic Information System; MFD/FD8: Multiple Flow

Direction; MFD-md: Multiple Flow Direction based on Maximum Downslope Gradient; SCA: Specific Catchment Area; TMFD/MDinf: Triangular Multiple

Flow Direction; TWI: Topographic Wetness Index 


\section{Acknowledgements}

The authors would like to thank the autonomous Province of Bolzano/Bozen.

\section{Authors' contributions}

PM created the main idea and the structure of the methods, carried out the data processing and participated in the manuscript drafting. FF contributed to discuss and review, participated in the design of the study and in the manuscript drafting. AL verified the algorithm and supported the processing, participated in the design of the study and wrote manuscript. GB supervised the implementation and reviewed the manuscript. All authors read and approved the final manuscript

\section{Funding}

Not applicable.

\section{Availability of data and materials}

The datasets generated during the current study are available from the corresponding author on reasonable request.

\section{Competing interests}

The authors declare that they have no competing interests.

Received: 4 February 2019 Accepted: 21 June 2019

Published online: 29 July 2019

\section{References}

1. Ågren AM, Lidberg W, Strömgren M, Ogilvie J, Arp PA. Evaluating digital terrain indices for soil wetness mapping-a Swedish case study. Hydrol Earth Syst Sci. 2014;18(9):3623-34.

2. Bauer J, Rohdenburg H, Bork HR. Ein Digitales Reliefmodell Als Vorraussetzung Für Ein Deterministisches Modell Der Wasser-Und StoffFlüsse. Landschaftsgenese Und Landschaftsökologie. 1985;10:1-15.

3. Böhner J, Selige T. Spatial prediction of soil attributes using terrain analysis and climate regionalisation. In: Göttinger Geogr. SAGA-Analyses and Modelling Applications; 2006. Abh, no. 115.

4. Brovelli MA, Mitasova H, Neteler M, Raghavan V. Free and open source desktop and web Gis solutions. Applied Geomatics. 2012;4(2):65-6.

5. Cohen JM, Ernst KC, Lindblade KA, Vulule JM, John CC, Wilson ML. Local topographic wetness indices predict household malaria risk better than land-use and land-cover in the Western Kenya highlands. Malar J. 2010;9(1):328.

6. Conrad O, Bechtel B, Bock M, Dietrich H, Fischer E, Gerlitz L, Wehberg J, Wichmann $V$, Böhner J. System for automated geoscientific analyses (Saga) V. 2.1. 4. Geosci Model Dev. 2015;8(7):1991-2007.

7. Costa-Cabral MC, Burges SJ. Digital elevation model networks (Demon): a model of flow over hillslopes for computation of contributing and dispersal areas. Water Resour Res. 1994;30(6):1681-92.

8. Erskine RH, Green TR, Ramirez JA, MacDonald LH. Comparison of grid-based algorithms for computing upslope contributing area. Water Resour Res. 2006;42(9). https://doi.org/10.1029/2005WR004648.

9. Evans IS. An integrated system of terrain analysis and slope mapping. Zeitschrift Fur Geomorphologie. 1980;36:274-95.

10. Fairfield J, Leymarie P. Drainage networks from grid digital elevation models. Water Resour Res. 1991;27(5):709-17.

11. Freeman TG. Calculating catchment area with divergent flow based on a regular grid. Comput Geosci. 1991;17(3):413-22.

12. Google Trends Data. (2019). https://trends.google.com/trends/ explore?date $=2004-01-01 \% 202019-01-01 \& q=$ OGIS,GRASS\%20GIS,SAGA\%20GIS,Whitebox\%20GAT,ArcGIS. Accessed 3 Apr 2019.

13. Gruber S, Peckham S. Land-surface parameters and objects in hydrology. Dev Soil Sci. 2009;33:171-94.

14. Haralick RM. Ridge and valley detection on digital images. Comput Vis Graph Image Process. 1983;22(1):48-38.

15. Heerdegen RG, Beran MA. Quantifying source areas through land surface curvature and shape. J Hydrol. 1982:57(3-4):359-73.

16. Higginbottom TP, Field CD, Rosenburgh AE, Wright A, Symeonakis $E$, Caporn SJM. High-resolution wetness index mapping: a useful tool for regional scale wetland management. Ecol Inform. 2018;48(November):89-96 https://doi.org/10.1016/j.ecoinf.2018.08.003.

17. Horn BKP. Hill shading and the reflectance map. Proc IEEE. 1981;69(1):14-47.
18. Jolma A, Ames DP, Horning N, Mitasova H, Neteler M, Racicot A, Sutton T. Chapter ten free and open source geospatial tools for environmental modelling and management. Dev Integr Environ Assess. 2008;3:163-80.

19. Khandve $P$, Mokadam AM. Application of GIS in environmental engineering. In: Proceedings of National Conference on environment pollution and management. Aurangabad; 2011. p. 244-50. ISBN: 978819049588.

20. Kopecký M, Čižková Š. Using topographic wetness index in vegetation ecology: does the algorithm matter? Appl Veg Sci. 2010;13(4):450-9.

21. Lea NL. An aspect driven kinematic routing algorithm. In: Overland Flow: Hydraulics and Erosion Mechanics, vol. 147; 1992. p. 175.

22. Lindsay JB. Whitebox gat: a case study in Geomorphometric analysis. Comput Geosci. 2016;95:75-84

23. Moore ID, Gessler PE, Nielsen GA, Peterson GA. Soil attribute prediction using terrain analysis. Soil Sci Soc Am J. 1993;57(2):443-52.

24. Moore ID, Grayson RB, Ladson AR. Digital terrain modelling: a review of hydrological, geomorphological, and biological applications. Hydrol Process. 1991;5(1):3-30.

25. Neteler M, Bowman MH, Landa M, Metz M. GRASS Gis: a multi-purpose open source Gis. Environ Model Softw. 2012;31:124-30.

26. Neteler M, Mitasova H. Open source software and GIS. In: Open source Gis. Boston, MA: Springer US; 2008. p. 1-6.

27. O'Callaghan JF, Mark DM. The extraction of drainage networks from digital elevation data. Comput Vis Graph Image Process. 1984;28(3):323-44.

28. Planchon O, Darboux F. A fast, simple and versatile algorithm to fill the depressions of digital elevation models. Catena. 2002;46(2-3):159-76.

29. Pourali SH, Arrowsmith C, Chrisman N, Matkan AA, Mitchell D. Topography wetness index application in flood-risk-based land use planning. Appl Spat Anal Policy. 2016;9(1):39-54.

30. Provincia Autonoma di Bolzano - Alto Adige: Modelli digitali altimetrici. (2019). http://www.provincia.bz.it/natura-ambiente/natura-territorio/ cartografia/modelli-digitali-altimetrici.asp. Accessed 23 Jan 2019.

31. QGIS Development Team, 2019. QGIS Geographic Information System. Open Source Geospatial Foundation Project. http://qgis.osgeo.org. Accessed 3 Apr 2019

32. Qin C-Z, Zhu A-X, Pei T, Li B-L, Scholten T, Behrens T, Zhou C-H. An approach to computing topographic wetness index based on maximum downslope gradient. Precis Agric. 2011;12(1):32-43.

33. Quinn PFBJ, Beven K, Chevallier P, Planchon O. The prediction of hillslope flow paths for distributed hydrological modelling using digital terrain models. Hydrol Process. 1991;5(1):59-79.

34. Seibert J, McGlynn BL. A new triangular multiple flow direction algorithm for computing upslope areas from gridded digital elevation models. Water Resour Res. 2007;43(4). https://doi.org/10.1029/2006WR005128.

35. Schmidt F, Persson A. Comparison of DEM data capture and topographic wetness indices. Precis Agric. 2003;4(2):179-92.

36. Steiniger S, Bocher E. An overview on current free and open source desktop Gis developments. Int J Geogr Inf Sci. 2009;23(10):1345-70.

37. Steiniger S, Hunter AJS. The 2012 free and open source Gis software map-a guide to facilitate research, development, and adoption. Comput Environ Urban Syst. 2013;39:136-50.

38. Tarboton DG. A new method for the determination of flow directions and upslope areas in grid digital elevation models. Water Resour Res. 1997:33(2):309-19.

39. Tian B. GIS technology applications in environmental and earth sciences. 1st ed. Boca Raton: CRC Press; 2016.

40. Travis MR, Elsner GH, Iverson WD, Johnson CG. VIEWIT: computation of seen areas, slope, and aspect for land-use planning, vol. 70. Berkeley: Pacific Southwest Research Station, Forest Service, US Department of Agriculture; 1975. p. 11. Gen. Tech. Rep. PSW-GTR-11

41. Wang L, Liu H. An efficient method for identifying and filling surface depressions in digital elevation models for hydrologic analysis and modelling. Int J Geogr Inf Sci. 2006;20(2):193-213.

42. Western AW, Grayson RB, Blöschl G, Willgoose GR, McMahon TA. Observed spatial Organization of Soil Moisture and its Relation to terrain indices. Water Resour Res. 1999:35(3):797-810.

43. Zevenbergen LW, Thorne CR. Quantitative analysis of land surface topography. Earth Surf Process Landf. 1987;12(1):47-56.

\section{Publisher's Note}

Springer Nature remains neutral with regard to jurisdictional claims in published maps and institutional affiliations. 